\title{
Development of a specific exercise programme for professional orchestral musicians
}

\author{
Cliffton Chan, ${ }^{1}$ Tim Driscoll, ${ }^{2}$ Bronwen Ackermann ${ }^{1}$
}

\begin{abstract}
${ }^{1}$ Discipline of Biomedical Science, Sydney Medical School, The University of Sydney, Lidcombe, Australia ${ }^{2}$ School of Public Health, Sydney Medical School, The University of Sydney, Camperdown, Australia
\end{abstract}

\section{Correspondence to}

Cliffton Chan, Discipline of

Biomedical Science, Sydney

Medical School, The University

of Sydney, PO Box 170 ,

Lidcombe, NSW 1825

Australia;

cliffton.chan@sydney.edu.au

Accepted 2 November 2012

Published Online First

4 December 2012

\begin{abstract}
Background Musculoskeletal problems are common in professional orchestral musicians, and little is known about effective prevention strategies. Exercise is suggested to help in reducing work-related upper limb disorders and accordingly a trial of a specific exercise programme for this population was planned. Formative and process evaluation procedures were undertaken during the development of the programme to ensure high methodological credibility.
\end{abstract}

Methods Literature reviews on exercise interventions for musicians as well as for neck, shoulder, abdominal, lower back and hip/pelvic body regions were undertaken. Current preventative and rehabilitation models were reviewed including undergraduate curriculums, postgraduate training programmes, and opinion from academic and clinical physiotherapists. Five series of progressive exercises were developed as a result. These were reviewed by expert physiotherapists who were blinded to the proposed progression difficulty of the exercises. A revised draft was produced for further review. This final programme was pilot trialed and feedback from the participants and physiotherapist instructors were obtained.

Results No evidence-based literature regarding an exercise programme for professional orchestral musicians was found. An exercise programme was subsequently developed with progressive stages that followed an adapted exercise prevention and rehabilitation model. The blinded ranking of each exercise series produced varied results particularly in the abdominal and shoulder series. Feedback from the participants and instructors in the pilot study resulted in changes to the exercise difficulty, and the class format and structure.

Conclusions Using available evidence on exercise prescription in collaboration with clinical consensus and current best practice, a specific exercise programme was developed to prevent and/or reduce occupational injuries in professional orchestral musicians.

Musicians suffer a high incidence and severity of performance-related musculoskeletal disorders (PRMDs). ${ }^{1}$ National and international surveys document the lifetime prevalence of PRMDs in professional orchestral musicians as anywhere between $39 \%$ to $87 \%$, depending on the survey methodology, and a current playing-related pain point prevalence of $50 \%$ in Australian professional orchestral musicians. ${ }^{1-3}$ Professional orchestral musicians develop highly selective patterns of neuromuscular activation in response to the precise playing demands occurring over extensive periods of time. ${ }^{4}$ This ongoing cumulative load on the musculoskeletal and neuromuscular systems may result in adaptive changes including postural imbalances and asymmetrical strength and mobility, especially of the trunk and upper limbs. ${ }^{5} 6$ Despite this, there has been little investigation of healthcare approaches to the management of these PRMDs, and there is a need for research to provide better evidence of how to effectively manage them.

In occupational health literature, exercise is recommended as an appropriate preventative intervention for work-related injuries. ${ }^{7}$ However, there is little evidence to support the use of exercise for effective injury prevention or management in professional orchestral musicians. ${ }^{8}$ One small study involving professional musicians from one orchestra found benefits in reduced PRMD incidence and severity following the implementation of a 15 -week intervention package including some generic exercises. ${ }^{9}$ Three other studies investigated the effect of exercise programmes on university music students. These studies included generic strength, postural or aerobic exercises and were reported to reduce the presence, frequency and intensity of PRMDs and to improve instrumental playing posture. ${ }^{10-12}$ It was decided that while concepts of core stability would be retained, as this appeared to be a common feature associated with the positive outcomes of these trials, it would be worth developing much more specific and targeted exercises to implement in the current study.

This paper describes the development of a programme aimed to adapt or create exercises specifically targeted for professional orchestral musicians based on the problematic regions identified in PRMD literature and analysis of the loading created by instrumental movements and postures. As no available evidence on best practice existed, an exercise programme was developed that had high face validity and could be implemented consistently when trialled nationally.

The article reported here has three aims:

A. To present the methods used to develop an evidence-based exercise programme that targets prevention of common injuries in professional orchestral musicians

B. To describe the components of the programme C. To trial the programme.

\section{METHODS}

\section{Phase 1. Development of the exercise programme}

The exercise programme was developed by integrating evidence obtained from a comprehensive literature review, national physiotherapy undergraduate and postgraduate courses, and common exercise prescription approaches. The resulting 
Figure 1 Flowchart of literature search results of musician exercise intervention literature in Medline, Cochrane, PEDro, CINAHL and AMED databases.

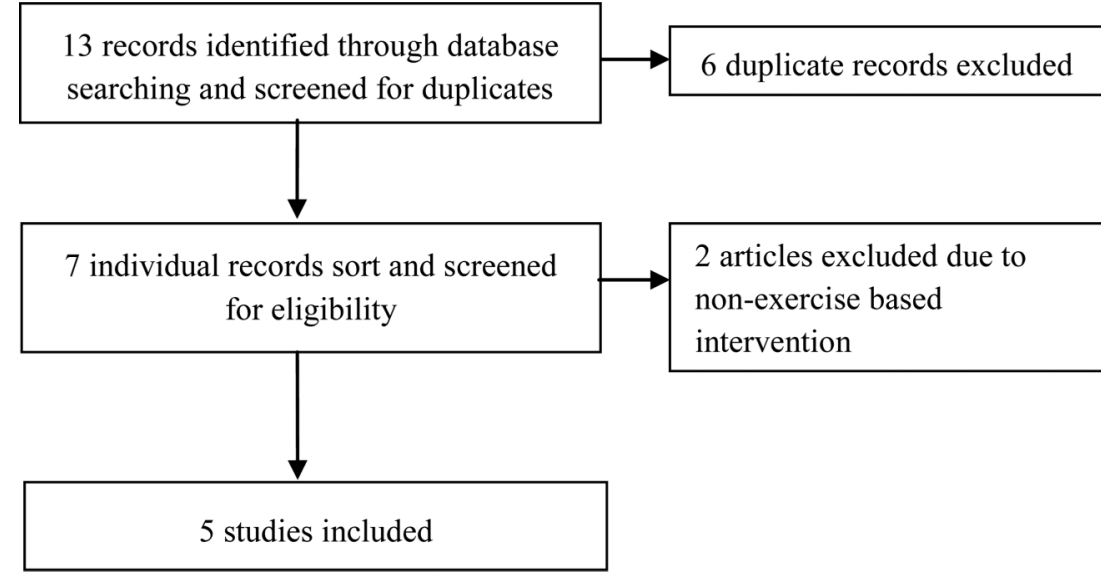

draft programme was then subjected to an external formative evaluation process.

A literature search was conducted in April 2010 using Medline, Cochrane Clinical Trials, PEDro, CINAHL and AMED. The search terms included musician with exercise, prevention, rehabilitation and programme using 'or' and 'and' as Boolean operators that yielded five studies suitable for inclusion (figure 1). A broader literature search was also carried out to include combinations of exercise interventions and body regions. The search terms included exercise programme, prevention, management, rehabilitation and stabilisation with neck, cervical spine, lower back, lumbar spine, shoulder, glenohumeral, abdominal, hip and pelvis using 'or' and 'and' as Boolean operators from which 68 studies were included as potential resources for this project (figure 2). The latter terms were chosen as these were common injury regions identified through previous literature reviews, and through a large-scale baseline assessment of the premier symphony orchestras of Australia as part of the Sound Practice study. ${ }^{1}{ }^{13}$ Limits on both literature searches included 'human studies' and 'English'.

Figure 2 Flowchart of a literature search of exercise interventions for different body regions in Medline, Cochrane, PEDro, CINAHL and AMED databases.
To identify best practice in exercise programme implementation, physiotherapists nationally-acknowledged as experts in the field of exercise prescription were interviewed. Current teaching practice from two well-established undergraduate physiotherapy curriculums and six post-graduate sports exercise courses in Australia were also incorporated. Five series of exercises with progressive stages were developed to target the common problematic PRMDs in the orchestral musician population.

Four physiotherapists (each with over 20 years of experience) were invited to participate in a formative evaluation process. These physiotherapists had worked with musicians and were known for their use of exercise in rehabilitation. Two also worked in an academic environment. The illustrated series of proposed exercises and instructions were presented to each of the physiotherapists individually in a randomised order. They were instructed to rank each series from easiest to most challenging so that 'the best order of progression is achieved', and provide feedback on the exercises. The physiotherapists were also asked whether they felt any other exercises should be

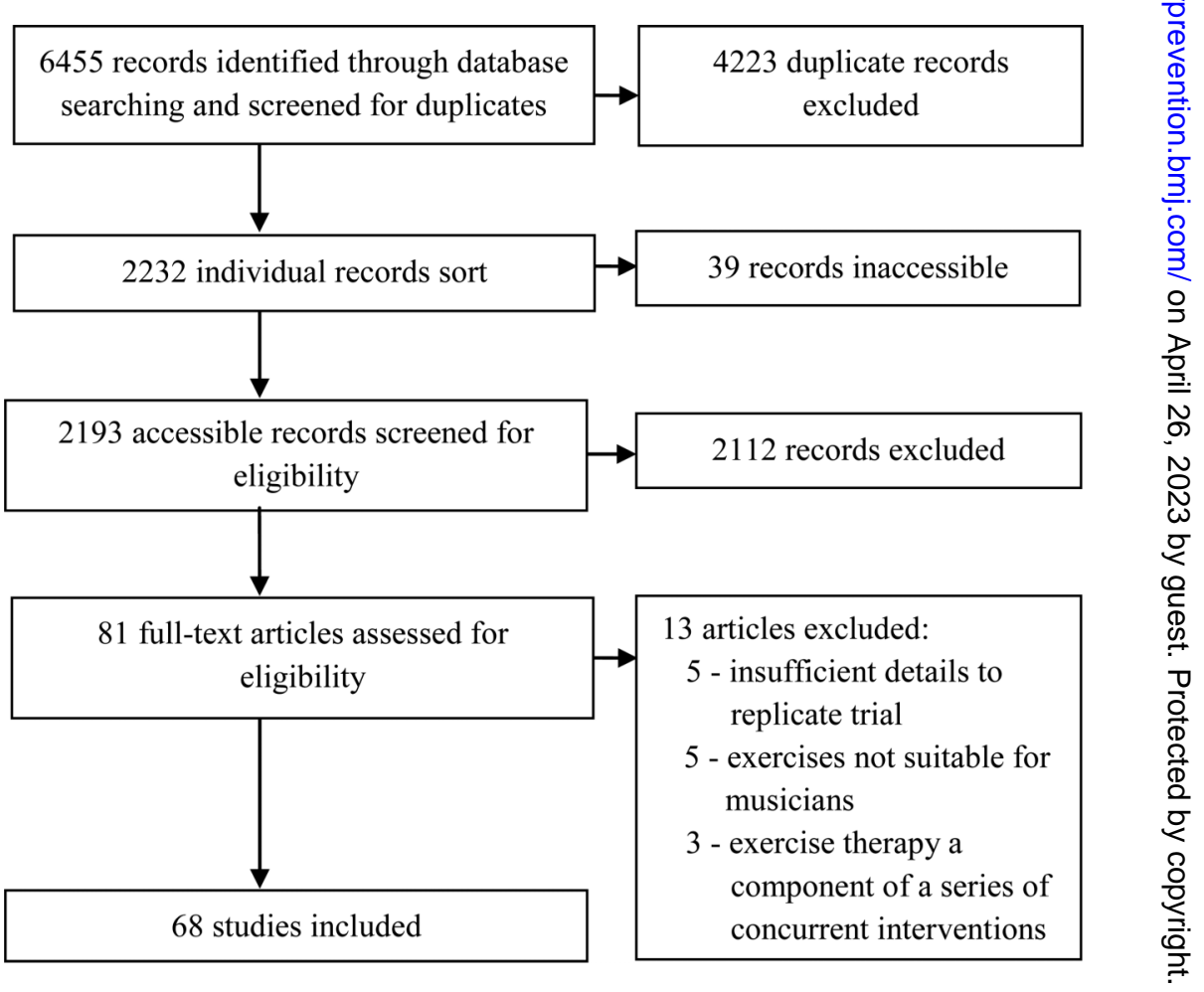


added or replaced in the programme. Discrepancies between the physiotherapists' suggested order and the initial order of progressions were considered along with the detailed comments about the exercise choice. A final draft was produced by the authors after discussing the changes with two of the physiotherapists involved in the initial ranking process.

This programme was designed to be trialled at a national level and hence involved the recruitment of experienced physiotherapists from around Australia to run programmes. To improve the reliability of programme delivery, a detailed manual was produced to instruct both physiotherapists and participants in how to perform the exercise programme. A training session for participating physiotherapists was conducted to encourage a standardised approach to delivery of the programme and adherence to the research protocol. This involved learning the exercises, reviewing the exercise instructions, reinforcing the safety precautions and procedure of progression through each series, and outlining the class format and structure. The physiotherapists were required to observe one class run by one of the course developers before conducting an exercise class themselves. The physiotherapists were required to have Clinical Pilates training to further improve the consistency of their approach, particularly for the early stages of each exercise series.

The exercise classes were conducted at one orchestra's premises, outside of work hours (before rehearsal, in the lunch hour or after rehearsal) to make the programme as convenient and accessible as possible. This was decided in collaboration with orchestral management, whose support was important to ensure programme viability, improve participation and reduce attrition. Each class was proposed to be $40 \mathrm{~min}$ long: $5 \mathrm{~min}$ each of warm-up and cool-down, and $30 \mathrm{~min}$ of exercises. The programme was designed to run over 8 weeks, with two classes per week. This was expected to produce changes in neuromuscular patterning and strength gains as a result of neural and physiological adaptations. ${ }^{14} 15$

For cost effectiveness reasons, a group setting was chosen as the delivery method. At the initial exercise class, the participants did warm-ups, cool-downs and Stage One of each series together. From week two, participants were instructed to use the exercise manual to continue exercises from Stages One to Six with physiotherapist guidance and supervision.

Phase 2. Pilot trial of the exercise programme

A trial was undertaken with professional musicians from one of the symphony orchestras to evaluate the different elements of the exercise programme. This included the ratio of physiotherapist to participants, exercise instructions, class times and length, and overall class structure. Participants were supplied with a record sheet to monitor the dosage performed for each exercise and the progress of the stage in each exercise series. This record also allowed the physiotherapist to track progress over the course of the programme. A comments section was included in the record to allow the physiotherapist to write exercise reminders for the participant. Participants and physiotherapists were able to provide feedback to the authors throughout the trial and at the end of the trial via semistructured interviews. A decision would be made by the authors (CC and BA) whether the feedback necessitated changes to be made to the programme.

\section{RESULTS}

Five articles related to musicians and exercise therapy were identified from the literature review (figure 1). ${ }^{9-12} 16$ A larger number of exercise therapy clinical trials and systematic reviews were found for non-musician populations (figure 2). Exercise programmes were excluded if they had insufficient detail to replicate the trial, exercises were functionally unsuitable for musicians, and the exercise programme was a component of a series of concurrent interventions.

An exercise model was developed to best integrate existing evidence and strategies identified by clinicians and researchers (figure 3). Most of the programme was based on fundamental sports rehabilitation principals resulting in a programme that consisted of: (1) activating the muscles concerned with stability and satisfactory postural control of the region in the early stages; (2) added external perturbations or resistive loads in the middle stages; and in the late stages; (3) exercises were used that both increased muscle endurance demands and were applied in a specific functional position relating to common patterns of movement during instrumental performance. ${ }^{17-20}$ Other exercise design considerations to take account of the musicians' normal work demands included the need to reduce load on the wrist joints by leaning on the forearms in upper limb weight-bearing positions, and using loops in the resistance band rather than having to grip the band with the hand when performing the exercise.

\section{Neck series}

Progressions of cervical spine exercise therapy strengthening the deep neck flexors and extensors were adapted for musicians. ${ }^{21} 22$
Figure 3 Adaptation of common elements in early, mid and end-stages of injury prevention/rehabilitation exercise programmes.

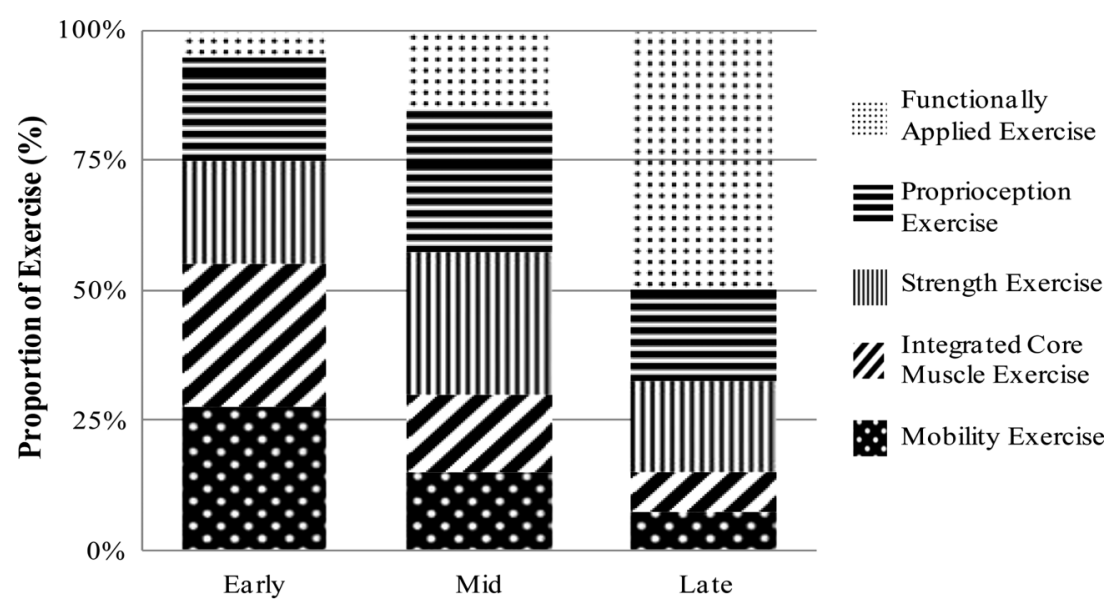

Stage of Injury Prevention or Rehabilitation 
Table 1 Proposed order of progression of series, by reviewers

\begin{tabular}{|c|c|c|c|c|c|c|c|c|c|c|c|c|c|c|c|c|c|c|c|c|}
\hline \multirow{3}{*}{$\begin{array}{l}\text { Author proposed order of } \\
\text { exercise progressions }\end{array}$} & \multicolumn{20}{|c|}{ Series of exercise } \\
\hline & \multicolumn{4}{|c|}{ Neck } & \multicolumn{4}{|c|}{ Shoulder } & \multicolumn{4}{|c|}{ Spinal } & \multicolumn{4}{|c|}{ Abdominals } & \multicolumn{4}{|c|}{ Hip } \\
\hline & \multicolumn{4}{|c|}{ Reviewer } & \multicolumn{4}{|c|}{ Reviewer } & \multicolumn{4}{|c|}{ Reviewer } & \multicolumn{4}{|c|}{ Reviewer } & \multicolumn{4}{|c|}{ Reviewer } \\
\hline 1 & * & 1 & $\dagger$ & 1 & * & 1 & $\dagger$ & 1 & * & 1 & 3 & 2 & 3 & 1 & 1 & 1 & $\dagger$ & 1 & 1 & 1 \\
\hline 2 & * & 2 & 1 & 2 & $\dagger$ & 2 & 1 & 2 & * & 2 & 2 & 3 & 4 & 2 & 2 & 3 & 2 & 2 & 2 & 2 \\
\hline 3 & * & 3 & 5 & 4 & 4 & 3 & 5 & 3 & * & 3 & 1 & 1 & 5 & 4 & 5 & 2 & 1 & 3 & 3 & 3 \\
\hline 4 & * & 4 & 4 & 3 & 1 & 4 & 4 & 5 & $*$ & 6 & 4 & 6 & 6 & 6 & 4 & 4 & 5 & 4 & 4 & 4 \\
\hline 6 & * & 5 & 2 & 6 & 3 & 6 & 2 & 6 & * & 5 & 5 & 5 & $\dagger$ & 5 & 6 & 6 & 3 & 6 & 5 & 6 \\
\hline
\end{tabular}

*Denotes the physiotherapist reviewer did not provide a numerical response.

tDenotes the reviewer suggests a change to this exercise.

In the final stages, varying degrees of resistance was applied to the neck from a variety of angles to load the deep neck muscle system in an attempt to replicate the challenges of maintaining a healthy neck position while sustaining the weight of instruments.

\section{Shoulder series}

A progressive series of scapular stability and rotator cuff exercises were included focusing on restoring shoulder muscle balance and movement control. ${ }^{23}$ This progressed to stages that added resistance and increased the functional context of the exercises into instrumental performance biomechanical patterning. $^{24}$

\section{Spinal series}

The early stages of the spinal series consisted of low load activation of the lumbar multifidis. ${ }^{25}$ Later stages progressively integrated the lumbar multifidus into a range of more functional activities with appropriate use of load and a variety of external perturbations to mimic the movements used during performance. $^{2627}$

\section{Abdominal series}

A focus on activation of the abdominal muscles during commonly prescribed Clinical Pilates exercises was included, progressing into more difficult stages using an unstable base of support. ${ }^{28} 29$ Finally, these exercises were adapted into more functional activation patterns in both sitting and standing. ${ }^{30}$

\section{Hip series}

A focus was placed on the endurance and strength of the gluteal muscle group, including hip abduction and external rotation exercises. ${ }^{31}$ The intermediate stages combined these exercises with upper body movement. ${ }^{32}$ The final stage incorporated the elements in the previous exercises in all three planes of movement. ${ }^{33}$

\section{Warm-up and cool-down}

A warm-up component was included involving diaphragmatic breathing, and large body movements such as spinal curl downs, neck and shoulder rolls, and thoracic and lumbar rotations. ${ }^{34}$ A cool-down component repeated some of the exercises in the warm-up component, with the addition of sustained stretches (of the upper trapezius, levator scapulae, quadratus lumborum, oblique abdominis and hamstrings). ${ }^{35}$

A summary of the ranking scores from the expert physiotherapists' randomised review process is shown in table 1. The physiotherapists' ranking of difficulty for the exercises were similar in the hip series, and moderately similar in the neck and spinal series. The results that differed most between the physiotherapists related to the abdominal and shoulder series. In reference to the selection of exercises, one reviewer commented 'I have seen many musicians with pain who have too much stability and can't relax these muscles' in relation to the abdominal and spinal series. The abdominal, spinal and shoulder series of the exercise programme were subsequently modified in particular, exercises early in the series that were considered too difficult were adjusted to provide more support and those considered too easy or 'too much stability' later in the programme had more dynamic movement elements added.

\section{Pilot trial}

A total of 13 musicians, nine females and four males, participated in this trial with a mean age of 44.7 years (SD 10.3). The participants' mean years of professional playing time was 21.8 years (SD 13.0). String instruments were the most commonly played by the musicians (table 2 ). Comments received during the trial and at the semi-structured interviews indicated resistance band difficulties in the shoulder series and a need for more resistance in the abdominal series; and that class structure and schedule, and a small number of exercise instructions in the exercise manual, needed minor modifications.

The levels of resistance band were upgraded in the intermediate stages of the abdominal exercises, and downgraded for the shoulder exercises. The class structure was modified because participants required more assistance in the early stages of the exercises - the group class format was increased from 1 week to 2 weeks, and the individualised progression format was initiated from week three. A physiotherapist to participant ratio of $1: 6$ appeared to be the best compromise to provide satisfactory supervision and allow maximum participation. The highest attendance rate occurred when the class was held during the lunch break between rehearsals. The duration of the exercise class had to be reduced to allow adequate time for musicians to prepare to return to rehearsal, leaving $25 \mathrm{~min}$ for

Table 2 Instruments played by the musicians in the pilot trial

\begin{tabular}{ll}
\hline Instrument & Count $(\mathbf{n = 1 3})$ \\
\hline Violin & 2 \\
Viola & 3 \\
Cello & 3 \\
Double Bass & 1 \\
Flute & 1 \\
Clarinet & 1 \\
Oboe/Cor Anglais & 2 \\
\hline
\end{tabular}


Table 3 List of exercises in final exercise programme

\begin{tabular}{|c|c|c|c|c|c|c|}
\hline Series & Stage 1 & Stage 2 & Stage 3 & Stage 4 & Stage 5 & Stage 6 \\
\hline Neck & $\begin{array}{l}\text { Deep neck } \\
\text { flexor in supine }\end{array}$ & $\begin{array}{l}\text { Deep neck flexor and } \\
\text { extensor co-activation } \\
\text { in supine }\end{array}$ & $\begin{array}{l}\text { Deep neck flexor and } \\
\text { extensor co-activation with } \\
\text { cervical movements in } 4 \\
\text { point kneel }\end{array}$ & $\begin{array}{l}\text { Deep neck flexor and } \\
\text { extensor activation with } \\
\text { cervical rotation in } 4 \text { point } \\
\text { kneel }\end{array}$ & $\begin{array}{l}\text { Deep neck stabilisation } \\
\text { with cervical movements } \\
\text { under constant light } \\
\text { resistance }\end{array}$ & $\begin{array}{l}\text { Deep neck stabilisation } \\
\text { with cervical movements } \\
\text { under changing resistance }\end{array}$ \\
\hline Shoulder & $\begin{array}{l}\text { Middle and } \\
\text { lower trapezius } \\
\text { activation }\end{array}$ & $\begin{array}{l}\text { Serratus anterior } \\
\text { activation in Weight } \\
\text { Bearing position }\end{array}$ & $\begin{array}{l}\text { Scapular stability with } \\
\text { thoracic movements }\end{array}$ & $\begin{array}{l}\text { Supported scapular } \\
\text { Stability with resisted } \\
\text { arm movements }\end{array}$ & $\begin{array}{l}\text { Unsupported dynamic } \\
\text { scapular stability with arm } \\
\text { and trunk movements }\end{array}$ & $\begin{array}{l}\text { Unsupported dynamic } \\
\text { scapular stability with arm } \\
\text { and full body movement }\end{array}$ \\
\hline Spinal & Prone leg lift & $\begin{array}{l}\text { Swimming arm and } \\
\text { leg }\end{array}$ & Single leg slide in 4 point & Superman arm and legs & $\begin{array}{l}\text { Sitting on dura disc forward } \\
\text { lean }\end{array}$ & $\begin{array}{l}\text { Sitting or standing on dura } \\
\text { disc forward lean in multi } \\
\text { directions }\end{array}$ \\
\hline Abdominals & $\begin{array}{l}\text { Single leg fall } \\
\text { out }\end{array}$ & Single leg circles & $\begin{array}{l}\text { Opposite leg and arm fall out } \\
\text { on unstable surface }\end{array}$ & $\begin{array}{l}\text { Opposite leg and arm } \\
\text { circles on unstable } \\
\text { surface }\end{array}$ & $\begin{array}{l}\text { Abdominal activation with } \\
\text { resistance in sitting }\end{array}$ & $\begin{array}{l}\text { Abdominal activation with } \\
\text { resistance in standing }\end{array}$ \\
\hline Hip & $\begin{array}{l}\text { Deep hip } \\
\text { external rotator } \\
\text { activation }\end{array}$ & $\begin{array}{l}\text { Deep hip external } \\
\text { rotator activation with } \\
\text { sit to stand }\end{array}$ & $\begin{array}{l}\text { Deep hip stabilisers with } \\
\text { resisted stepping and hip } \\
\text { abduction }\end{array}$ & $\begin{array}{l}\text { Single leg stance with } \\
\text { upper body movement }\end{array}$ & $\begin{array}{l}\text { Brolga with upper body } \\
\text { movement }\end{array}$ & Star excursion balance \\
\hline
\end{tabular}

the exercise component and 5 min for each of the warm-up and cool-down. The final structure and content of the programme are shown in table 3 .

\section{DISCUSSION}

The use of formative and process evaluation methods to develop a novel and targeted exercise programme for professional orchestral musicians appeared to be an effective strategy. The programme described here incorporated current fundamental sports rehabilitation principals, and adapted existing exercise therapy evidence in a logical and informed manner. ${ }^{17-35}$ The exercises and progressions chosen were based on those commonly taught and practiced in Australia in general physiotherapy modified to apply functionally to music performance. While the current study has been targeted specifically for professional orchestral musicians, this model for designing an exercise programme may help other researchers develop suitable programmes for other musician populations.

Musicians have a high reported incidence of neck problems across the instrumental groups. ${ }^{3}$ The research in cervical spine rehabilitation by Jull and colleagues influenced the inclusion of deep neck stabilisation and joint position sense principles in this series of exercises. ${ }^{21} 22$ There was also an emphasis on improving muscle efficiency by reducing commonly hypertonic muscles (ie, sternocleidomastoid, levator scapulae, upper trapezius) as well as decreasing overuse of breath control muscles (ie, scalenes).

Scapular stabilisation and rotator cuff endurance exercises are frequently-used approaches in the early stages of shoulder rehabilitation and shoulder instability programmes. ${ }^{23} 24$ These exercises were considered important for musicians because shoulder pain and dysfunction are commonly reported, and proximal stability at the shoulder has been shown to be important for increasing hand dexterity and strength. 51336

There is published evidence that the trunk muscles, in particular the deeper layers of the lumbar multifidus, are important for segmental spinal control and that these muscles may be inhibited in their control by the presence of low back pain (LBP). ${ }^{25} 26$ Optimising function of the lumbar multifidus reduces recurrence of acute LBP and disability. ${ }^{27} 37$ As LBP is relatively common in the professional musician population it was considered useful to include a series of exercises strengthening and challenging the lumbar multifidus in all three planes of movement. Large variations in the type of exercises used and the optimal mechanisms by which to activate these muscles exist in the literature. The rehabilitation strategies of
Richardson and colleagues were adopted and modified as appropriate for musicians. ${ }^{28}$

Much of the evidence on core training comes from LBP studies and Pilates trials and is well summarised elsewhere. ${ }^{28} 29$ There is evidence to support the re-training of proper transversus abdominis and internal oblique activation, especially when wind and brass players use abdominal musculature as an integral part of their breath control. It is likely that all musicians should use a variable degree of abdominal muscle activity to support a dynamic sitting and standing playing posture. Hence, a series of exercises incorporating the core abdominal muscles in different positions and a number of different external perturbations were included.

Lumbo-pelvic control is important to support dynamic upper body movements, such as those involved in instrumental playing. ${ }^{30}$ In this hip series, focus was placed on strengthening the gluteal muscle group to increase proprioceptive feedback and control of lower limb alignment. ${ }^{31} 32$ These elements were further challenged by integrating these exercises with upper body movements. To improve dynamic postural control during standing, the final stage used a combination of neuromuscular characteristics such as lower extremity proprioception, balance, flexibility and strength. ${ }^{33}$

The warm-up component encouraged large full body movements associated with playing an orchestral instrument and was based on recommendations from the sports literature. ${ }^{34}$ The cool-downs included moving the joints and muscles used in the exercise programme throughout range. ${ }^{35}$ Some static stretches were included for muscles that were considered to be hypertonic in musicians based on their patterns of use.

The most agreement in exercise progression and choice between the physiotherapist reviewers was for the hip series, and the least agreement was for the abdominal and shoulder series. The higher variance in reviewer feedback may indicate the large variety of prevention and rehabilitation approaches currently in practice, and the wide spectrum of strategies used for different populations, mostly arising from the sports literature. Two of the reviewers also commented that they typically only prescribed individualised sport/activity-specific programmes and felt it was difficult to comment on a generic group exercise programme.

The formative evaluation processes were vital in ensuring the programme was highly credible and likely to produce progressive and functional strengthening goals, with only some minor programme elements requiring further change during the process evaluation phase of the pilot trial. Working closely with orchestra management staff was necessary for the programme to be designed in a way that was compatible with the context and practicalities of the orchestral environment and schedules. 
During the pilot study, the feedback from participants indicated that exercises chosen did focus on areas where musicians had poor strength and control and did not overload structures already used during instrumental playing. There were selfreported positive changes in their posture and playing. The musicians indicated that the physiotherapist supervision was useful in teaching and refining basic exercise class components and techniques, enabling them to perform the exercises as well as possible. They reported enjoying the programme, and appreciated that the programme was available within the work schedule because many of them did not have enough time outside work to attend such classes. To play music at an elite level requires efficiency of effort as in any other high performance domain. There were concerns initially expressed by some musicians about developing muscle fatigue that may affect their practice or performance. Once the musicians realised that this exercise programme focused on movement control and increasing strength of supporting musculature in a functional context without negative effects on performance, they participated enthusiastically.

Feedback from physiotherapist instructors indicated that they felt that the exercises were at an appropriate level of difficulty for this population. They were surprised at the poor baseline strength of most of the targeted muscle groups in this elite population. These physiotherapists had considerable experience in prescribing exercises in other populations, usually in sports domains. They recognised there was a noticeable difference in the physical demands of music performance and understood the need for the specific approach adopted for this study.

\section{CONCLUSION}

Using a formative and process evaluation approach allowed the development and revision of a novel evidence-based exercise programme for professional orchestral musicians. The final programme incorporated available published evidence, clinical experience and expert feedback to design and test a proposed intervention thoroughly before widespread implementation and assessment. This exercise programme aims to optimise compliance and cost-efficacy that could accommodate a demanding

\section{What is already known about this subject}

- Professional orchestral musicians experience a high lifetime prevalence of performance-related musculoskeletal disorders (PRMDs)

- There are limited evidence-based intervention strategies for PRMDs

\section{What this study adds}

- A novel exercise programme was specifically designed for professional orchestral musicians to target the PRMDs reported in this occupational group by incorporating clinical experience, expert feedback and available published evidence

- Special considerations in the prescription of prevention and rehabilitation programmes for professional orchestral musicians, such as specific types of exercises and exercise progressions orchestra schedule. This programme is currently being trialled with a large group of professional orchestral musicians as part of the Sound Practice project to evaluate its effectiveness in addressing the incidence and intensity of PRMDs, and changes to the musicians' playing postures and effort levels.

Acknowledgements The authors would like to acknowledge the physiotherapists who assisted with the pilot trial exercise classes and the review processes involved in developing this programme.

Contributors CC, TD and BA have all made substantial contributions to the following: (1) the conception and design of the study, or acquisition of data, or analysis and interpretation of the data, (2) drafting the article or revising it critically for important intellectual content, and (3) the final approval of the attached manuscript.

Funding This work was supported by Australian Research Council, Australian Council of the Arts and the eight participating orchestras (Australian Opera and Ballet Orchestra, Sydney Symphony, Melbourne Symphony Orchestra, Orchestra Victoria, Adelaide Symphony Orchestra, Queensland Symphony Orchestra, Tasmanian Symphony Orchestra, West Australian Symphony Orchestra) (LP0989486).

\section{Competing interests None.}

Patient consent Obtained.

Ethics approval The University of Sydney Human Research Ethics Committee approved this project (HREC 12523).

Provenance and peer review Not commissioned; externally peer reviewed.

\section{REFERENCES}

1. Wu SJ. Occupational risk factors for musculoskeletal disorders in musicians: a systematic review. Med Probl Perform Art 2007;22:43-51.

2. Zaza C. Playing-related musculoskeletal disorders in musicians: a systematic review of incidence and prevalence. CMAJ 1998;158:1019-25.

3. Ackermann B, Driscoll T, Kenny DT. Musculoskeletal pain and injury in professional orchestral musicians in Australia. Med Probl Perform Art 2012;27:183-189.

4. Ackermann B. Therapeutic management of the injured musician. In: Sataloff RT, Brandonbrener AG, Lederman RJ. Performing arts medicine. 3rd edn. Narberth: Science \& Medicine, 2010:247-70.

5. Bejjani FJ, Kaye GM, Benham M. Musculoskeletal and neuromuscular conditions of instrumental musicians. Arch Phys Med Rehabil 1996:77:406-13.

6. Tubiana R, Chamagne P, Brockman R. Fundamental positions for instrumental musicians. Med Probl Perform Art 1989:4:73-6.

7. Boocock MG, McNair PJ, Larmer PJ, et al. Interventions for the prevention and management of neck/upper extremity musculoskeletal conditions: a systematic review. Occup Environ Med 2007;64:291-303.

8. Foxman I, Burgel BJ. Musician health and safety: preventing playing-related musculoskeletal disorders. AAOHN 2006;54:309-16.

9. de Greef $\mathbf{M}$, van Wijck R, Reynders K, et al. Impact of the Groningen exercise therapy for symphony orchestra musicians program on perceived physical competence and playing-related musculoskeletal disorders of professional musicians Med Probl Perform Art 2003;18:156-60.

10. Spahn C, Hildebrandt H, Seidenglanz K. Effectiveness of a prophylactic course to prevent playing-related health problems of music students. Med Probl Perform Art 2001;16:24-31.

11. Ackermann B, Adams R, Marshall E. Strength or endurance training for undergraduate music majors at a university. Med Probl Perform Art 2002;17:33-41.

12. Kava KS, Larson CA, Stiller CH, et al. Trunk endurance exercise and the effect in instrumental performance: a preliminary study comparing Pilates exercise and a trunk and proximal upper extremity endurance exercise program. Music Perform Res 2010;3:1-30

13. Fishbein M, Middlestadt SE, Ottati V, et al. Medical problems among ICSOM musicians: overview of a National Survey. Med Probl Perform Art 1988;3:1-8.

14. Gabriel DA, Kamen G, Frost G. Neural adaptations to resistive exercise. Sports Med 2006;36:133-49.

15. Knuttgen HG. Strength training and aerobic exercise: comparison and contrast. J Strength Cond Res 2007;21:973-8.

16. Shafer-Crane G. Repetitive stress and strain injuries: preventive exercises for the musician. Phys Med Rehabil Clin N Am 2006;17:827-42.

17. Brukner P, Khan K. Clinical sports medicine. Rev 3rd edn. Australia: McGraw-Hill, 2007;78-197.

18. Comfort $\mathbf{P}$, Abrahamson E. Sports rehabilitation and injury prevention. UK Wiley-Blackwell, 2010;223-463. 
19. Lephart SM, Pincivero DM, Giraldo JL, et al. The role of proprioception in the management and rehabilitation of athletic injuries. Am J Sports Med 1997;25:130-7.

20. Hodges PW. The role of the motor system in spinal pain: implications for rehabilitation of the athlete following lower back pain. J Sci Med Sport 2000;3:243-53.

21. Jull GA, Falla D, Treleaven J, et al. Retraining cervical joint position sense: the effect of two exercise regimes. J Orthop Res 2007;25:404-12.

22. Jull GA, Falla $D$, Vicenzino $B$, et al. The effect of therapeutic exercise on activation of the deep cervical flexor muscles in people with chronic neck pain. Man Ther 2009;14:696-701.

23. Brumitt J, Meira E. Scapula stabilization rehab exercise prescription. National Strength and Conditioning Association 2006;28:62-5.

24. Kibler WB, Sciascia AD, Uhl TL, et al. Electromyographic analysis of specific exercises for scapular control in early phases of shoulder rehabilitation. Am J Sports Med 2008;35:1780-98.

25. McGill SM, Grenier S, Kavcic N, et al. Coordination of muscle activity to assure stability of the lumbar spine. J Electromyogr Kinesiol 2003;13:353-9.

26. Hides J, Richardson CA, Hodges PW. Local segmental control. Therapeutic exercise for the lumbopelvic stabilisation: a motor control approach for the treatment and prevention of low back pain. 2nd edn. Edinbourgh: Churchill Livingstone, 2004;185-219.

27. Hauggaard A, Persson AL. Specific spinal stabilisation exercises in patients with low back pain —a systematic review. Phys Ther Rev 2007;12:233-48.

28. Richardson CA, Hides J, Hodges PW. Section 5: treatment and prevention of low back pain. Therapeutic exercise for lumbopelvic stabilization: a motor control approach for the treatment and prevention of low back pain. Edinburgh: Churchill Livingstone, 2004;173-246.

29. Emery K, De Serres SJ, McMillan A, et al. The effects of a Pilates training program on arm-trunk posture and movement. Clin Biomech 2010;25:124-30.

30. Kibler WB, Press J, Sciascia AD. The role of core stability in athletic function. Sports Med 2006;36:189-98.

31. Flack NAMS, Nicholson HD, Woodley SJ. A review of the anatomy of the hip abductor muscles, gluteus medius, gluteus minimus, and tensor fascia lata. Clin Anat 25:697-708.

32. Clark N, Herrington L. The knee. In: Comfort P, Abrahamson E. Sports rehabilitation and injury prevention. 1st edn. UK: Wiley-Blackwell, 2010:407-63.

33. Filipa A, Byrnes R, Paterno MV, et al. Neuromuscular training improves performance on the star excursion balance test in young female athletes. J Orthop Sports Phys Ther 2010:40:551-8.

34. Bahr R. Principles of injury prevention. In: Brukner P, Khan K. Clinical sports medicine. Rev 3rd edn. Australia: McGraw-Hill, 2007:78-101.

35. McNair PJ, Dombroski EW, Hewson DJ, et al. Stretching at the ankle joint: viscoelastic responses to holds and continuous passive motion. Med Sci Sports Exerc 2000;33:354-8.

36. Shim J, Park M, Lee S, et al. The effects of shoulder stabilisation exercise and shoulder isometric resistance exercise on shoulder stability and hand function. J Phys Ther Sci 2010;22:227-32.

37. Hides $\mathbf{J}$, Carolyn $\mathrm{R}$, Jull GA. Multifidus muscle recovery is not automatic after resolution of acute, first-episode low back pain. Spine 1996:21:2763-9.

\section{WHO launches Global Alliance for Care of the Injured}

Alert readers will recall that tertiary prevention involves caring for already injured victims in such a way that the consequences of their injuries are minimised. Consequently, WHO has launched a Global Alliance to address the millions of injury victims who suffer lifelong disability. This is a special problem in low-income countries where 'people with life-threatening but survivable injuries are six times more likely to die (36\% mortality) than in high-income settings (6\% mortality).' To diminish such inequalities, WHO launched Global Alliance for Care of the Injured (GACl) at the 66th World Health Assembly. GACl is a network of organisations and professional societies that collaborate to improve care for the injured. It now operates in 12 member organisations.

Building booms and regulatory gaps raise vulnerability to tornadoes and other disasters

We do not often think of tornadoes as the cause of preventable injuries, but as FairWarning points out, this is not necessarily true. It suggests that many in parts of America's tornado hot zone face dangers due to population growth and a tendency to discount threats. The centre of the latest disaster, Moore, Oklahoma, has seen its population surge since the 1960s, and much of the tornado-prone areas has not taken into account the dangers. Building codes do not require safe rooms despite research demonstrating how a few thousand dollars can save lives (The New York Times, Economics of Natural Hazards). 